\title{
Editorial: Biological Methanation or (Bio/Syn)-Gas Upgrading
}

\author{
Claire Dumas ${ }^{1 *}$, Lars Ditlev Mørck Ottosen ${ }^{2}$, Renaud Escudié ${ }^{3}$ and Paul Jensen ${ }^{4}$ \\ ${ }^{1}$ TBI, Université de Toulouse, CNRS, INRAE, INSA, Toulouse, France, ${ }^{2}$ Department of Engineering, Aarhus University, \\ Aarhus, Denmark, ${ }^{3}$ INRAE, Univ Montpellier, LBE, Narbonne, France, ${ }^{4}$ Advanced Water Management Centre, University of \\ Queensland, Brisbane, QLD, Australia
}

Keywords: biogas upgrading, methanogens, $\mathrm{CO}_{2}$ reduction, biological methanation, syngas upgrading

\section{Editorial on the Research Topic}

\section{Biological Methanation or (Bio/Syn)-Gas Upgrading}

This Research Topic is devoted to recent advances in the development of biological methanation or bio-syngas upgrading. The growth in fluctuating renewable electricity (photovoltaic and wind) has encouraged the further development of the source of power used in gas technologies; excess power from renewable energy is converted first to $\mathrm{H}_{2}$ by electrolysis of water (producing $\mathrm{H}_{2}$ and $\mathrm{O}_{2}$ ), and this is followed by methanation (producing $\mathrm{CH}_{4}$ from $\mathrm{H}_{2}$ and $\mathrm{CO}_{2}$ ). The present RT deals with the biological production of methane through biogas or syngas upgrading. Biological methanation is often associated with either anaerobic digestion or syngas production: in the first case, this is because the biological methanation reactor includes the same microbiology as an anaerobic digester; in the second case, this is because microorganisms have the advantage of being able to transform and/or to tolerate carbon monoxide or eventual inhibitor molecules present in the syngas. Despite the appearance of demonstration and pilot plants in Europe, the field of biological methanation is still at a low TRL level and is still in need of considerable research. The numbers of articles on the subject testify to this point. The subject has now begun to receive special attention, and a majority of the articles on this topic were published within the last couple of years.

The Research Topic contains seven articles: one on the subject of microbial community analysis; three on microbial processes and metabolism understanding during methanogenesis; one on the study of inhibition of methanogens; and one on development of an analytical system for lab experiments dedicated to the analysis of bio-electrical system (BES).

Ács et al. demonstrated that $\mathrm{AD}$ digester effluent contains the necessary microbiota for biomethanation in a batch system and that selection of the specific microbiology is promoted through feeding with $\mathrm{H}_{2}$ and $\mathrm{CO}_{2}$. The abundance of bacteria and archae show that Bacillus and Ruminococcus were promoted under these conditions. Concerning Archae, no reaarrangements was observed. Methanobacterium was the predominant archae genus in every reactor, and Methanothrix persisted for the first 4 weeks. An increase in Methanoculleus was observed during the adaptation to the sustained $\mathrm{H}_{2}$ and $\mathrm{CO}_{2}$ feeding, and this was the only genus found to be beneficial in the long term. This is encouraging for the development of biomethanation technologies, which apparently can rely on a selection from inherent microbiology in AD reactors and focus the research on the development of large-scale mass-transfer technology. This article has been viewed 1,033 times since it was published on 20/11/2019 online, attesting to the interest in this subject.

Chen et al. focused their research on the fact that microbiology (Methanobacterium congolense) performing biomethanation will experience the highly unnatural situation of low $\mathrm{CO}_{2}$ concentrations and high $\mathrm{H}_{2}$ concentrations if the biomethanation technology should perform very 
high conversions of $\mathrm{CO}_{2}$ to $\mathrm{CH}_{4}$, as required by the gas grid. Although this is not a situation found in most natural environments, these conditions can be found transiently in biomethanation reactors. Chen et al. showed that the $\mathrm{CO}_{2}$ affinity of methanogens most likely allows for $\mathrm{CO}_{2}$ conversion up to 95-99\% of $\mathrm{CH}_{4}$ at a reasonable rate, which should allow for biomethanation up to gas grid standards of $>95-98 \% \mathrm{CH}_{4}$. This article has been viewed 2,236 times since it was published online on $07 / 03 / 2019$.

Yee et al. studied the tempting approach of microbial electrosynthesis for biomethanation. In this technology, the cathode reaction of electrolysis $\left(\mathrm{H}^{+}\right.$reduction) is bypassed, and electrons are fed directly from a cathode to electroactive microbes with $\mathrm{CO}_{2}$ as an electron acceptor. Yee et al. showed that electroactive Methanosarcina (horonobensis and barkeri) were able to take electrons, via DIET and stimulated by Carbon granulates, from Geobacter metallireducens. However, M. barkeri was able to take electrons directly from a cathode surface, indicating that a closer study of uptake mechanisms, possibly trough genome information mining, could provide a better understanding of the potential of microbial electrosynthesis for biomethanation. This article has been viewed 3,471 times since it was published online on $2 / 04 / 2019$, attesting to the interest in this subject.

The work of Siegert and Tan was dedicated to the study of the stimulation of ammonotrophic methanogens by electricity. Experiments were carried out in H-type cells reactors with either an interest in ammonium oxidation coupled to hydrogen production or the testing of nitrogen removal coupled with methane production. First, they showed that ammonium oxidation can be coupled to $\mathrm{H}_{2}$ production in microbial electrolysis cells. Then, they tested the hypothesis whether wastewater nitrogen can be oxidized and used to produce methane. This article has been viewed 3,115 times since it was published online on $28 / 02 / 2019$, attesting to the interest in this subject.

An et al. were interested in the specific environments of shale gas and shale oil fields. They studied the structure of microbial communities in such environments and their evolution from fresh water, used as a fracturing fluid, to shale oil and gas reservoirs. These waters have the specificity to contains high saline (till $2.66 \mathrm{Meq}$ of $\mathrm{NaCl}$ ) and ammonium concentrations. Microbial community analyses reflected the presence of halophilic taxa, including Halomonas, Halanaerobium, and Methanohalophilus. Communities present in this shale oil reservoir enable the conversion of trimethylamine, or triglycinebetaine (GB), into ammonium and methane through syntrophic metabolism by Halanaerobium and Methanohalophilus. This article has been viewed 1,696 times since it was published on $07 / 03 / 2019$, attesting to the interest in this subject.

Siegert described the innovation he made in developing a potentiostat software to reduce the cost of hardware that uses potentiostat in BES research studies. Using a tubular wastewater treatment reactor for 10 days at two electrode potential values +0.300 and $-0.800 \mathrm{~V}$ demonstrated that the software presented similar properties to hardware potentiostat, and this can be used to scale BES. The results show that a simple proportional controller can replace expensive potentiostats for chronoamperometry. This article has been viewed 2,175 times since it was published on $30 / 11 / 2019$, attesting to the interest in this subject.

Seyedi et al. studied the toxicity of various aqueous pyrolysis liquids (APL) on methanogens. The characteristics of APL, high quantity of COD, numerous complex organic compounds, and ammonia content give them the opportunity to be used as co substrate in anaerobic digestion units. However, some APL organics and $\mathrm{NH}_{3}-\mathrm{N}$ can inhibit methane-producing microbes. The cause of inhibition is attributed to the presence of organic compounds in catalyzed APL (phenol, m-cresol, p-cresol, 2,4dimethylphenol, 3,5- dimethoxy-4-hydroxybenzaldehyde, 2,5dimethoxybenzyl alcohol, ethylbenzene, and styrene). This article has been viewed 1,346 times since it was published on 08/02/2019, attesting to the interest in this subject.

The Editors hope that the reader will find in this Research Topic a useful reference for inspiring significant progress in the field of biological methanation.

\section{AUTHOR CONTRIBUTIONS}

$\mathrm{CD}, \mathrm{LO}, \mathrm{RE}$, and PJ contributed equally to the editorial redaction of this Research Topic.

Conflict of Interest: The authors declare that the research was conducted in the absence of any commercial or financial relationships that could be construed as a potential conflict of interest.

Copyright (C) 2020 Dumas, Ottosen, Escudié and Jensen. This is an open-access article distributed under the terms of the Creative Commons Attribution License (CC BY). The use, distribution or reproduction in other forums is permitted, provided the original author(s) and the copyright owner(s) are credited and that the original publication in this journal is cited, in accordance with accepted academic practice. No use, distribution or reproduction is permitted which does not comply with these terms. 